\title{
Transcription Factor PU.1 Inhibits Aspergillus fumigatus Infection via Surfactant Protein-D
}

\author{
Sung-Su Kim ${ }^{\dagger} * *$ \\ Department of Biomedical Laboratory Science, Daejeon University, Daejeon 34520, Korea
}

\begin{abstract}
Aspergillosis is a life-threatening disease in individuals with compromised immune systems. Fungal invasion is a highly critical process during host cellular infection. Several papers have reported that transcription factors are responsible for the infection process. To investigate what transcription factors are involved in the process in an effort to inhibit fungal infection into cells, I checked the surfactant protein family and PU.1 transcription factor levels in A549 cells infected with A. fumigatus conidia. PU.1 and surfactant protein-D levels were reduced in cells infected with fungal conidia. I then observed an increase in surfactant protein-D on PU.1-overexpressed cells. Infection of A. fumigatus conidia was decreased in PU.1-overexpressed cells, whereas the suppression of PU.1 did not lead to any changes in cases of A. fumigatus conidia infection. These results indicate that PU.1 inhibits the infection of A. fumigatus conidia via the expression of surfactant protein-D, suggesting that PU.1 is a key transcription factor for protection against $A$. fumigatus invasion.
\end{abstract}

Key Words: Aspergillosis, Aspergillus fumigatus, PU.1, Surfactant Protein-D

\section{INTRODUCTION}

Invasive aspergillosis is a life-threatening pulmonary or systemic infection. Invasion of Aspergillus fumigatus (A. fumigatus) is the main cause of Aspergillus infection in humans (Segal, 2009; Sharon et al., 2011). A. fumigatus is classified as a group of opportunistic pathogens which exist ubiquitously in the natural environment (Segal, 2009). Depending on the health condition of the infected human, Aspergillus species can cause diseases ranging from local allergic reactions to invasive infections or even pneumonia (Barnes and Marr, 2006).

Surfactant proteins play a key role in the host defense mechanism. Pulmonary surfactant proteins are located on lung alveolar surfaces and consist of phospholipids and proteins (Whitsett and Weaver, 2002). Surfactant proteins are made by alveolar type II cells and Clara cells, the major seed cells of peripheral airway cells. Surfactant proteins have several functions; they reduce tension to prevent an alveolar collapse, prevent pathogens from spreading, and regulate immune reactions (Wright, 2005).

Pulmonary surfactant proteins (SP) are divided into two groups: hydrophobic surfactant proteins (SP-A and SP-B) and hydrophilic surfactant proteins (SP-C and SP-D). SP-B proteins regulate lung injuries during inflammation induced by the IgG immune complex (Yan et al., 2012). The SP-C type interacts with lipopolysaccharides and decreases the cytokine activity of macrophages (Augusto et al., 2003). SP-A and SP-D, as innate immune proteins, have been dem-

Received: March 28, 2018 / Revised: July 27, 2018 / Accepted: August 17, 2018

* Professor.

${ }^{\dagger}$ Corresponding author: Sung-Su Kim. Department of Biomedical Laboratory Science, Daejeon University, Daejeon 34520, Korea. Tel: +82-42-280-2903, Fax: +82-42-280-2904, e-mail: sungsu@dju.kr (C) The Korean Society for Biomedical Laboratory Sciences. All rights reserved.

(C) This is an Open Access article distributed under the terms of the Creative Commons Attribution Non-Commercial License (http://creativecommons.org/licenses/by-nc/3.0/) which permits unrestricted non-commercial use, distribution, and reproduction in any medium, provided the original work is properly cited. 
onstrated to be antibacterial (LeVine et al., 1998) and antifungal (McCormack et al., 2003). The expression of SP genes is regulated by several nuclear proteins, including thyroid transcription factor-1 (TTF-1) and hepatocyte nuclear factor-3 $\beta$ (HNF-3 $\beta$ ) (Zhou et al., 1996).

The transcription factor PU.1 is a member of the Etwenty-six family and is readily found in myeloid cells. PU.1 can increase the activation of the eosinophil granule gene, induce histone modification in dendritic cells, and increase IL-4 production in mast cells (Henkel and Brown, 1994; Gombart et al., 2003). In macrophages, PU.1 has an important role in differentiation processes (Lawrence and Natoli, 2011), and PU.1 induces lung inflammation in neutrophils by regulating the cell signaling process (Karpurapu et al., 2011). Moreover, the regulation of PU.1 expression may be a good therapeutic target for disease control during inflammation of the asthmatic airway (Qian et al., 2015).

In the present study, I used $A$. fumigatus conidia to demon strate the cellular response at the transcription level in human lung epithelial cells (A549). This study can provide a better understanding of the invasion processes occurring at the molecular level, and the findings imply that transcription factor PU.1 is a viable therapeutic agent for the treatment of a variety of fungal infections.

\section{MATERIAL AND METHODS}

\section{A. fumigatus strain and culture conditions}

A. fumigatus AF293 (wild type; WT) strains were used. A glucose-minimal medium with $0.1 \%(\mathrm{w} / \mathrm{v})$ of yeast extract (MMY) along with supplements was used for the general culture of the fungal strains (Kafer, 1977). Amounts of $5 \times$ $10^{5}$ conidia $/ \mathrm{mL}$ were inoculated on solid MMY and incubated at $37^{\circ} \mathrm{C}$ for $3 \sim 4$ days. A. fumigatus conidia were detached from agar plates. They were suspended in sterile ultrapure $\mathrm{H}_{2} \mathrm{O}$ with $0.02 \%$ Tween 80 . The resting conidia were washed two times and counted with a hemocytometer, after which they were stored at $4{ }^{\circ} \mathrm{C}$ until use (up to $48 \mathrm{~h}$ ). A549 cells from the human lung epithelial cell line were cultured in RPMI 1640 with 10\% fetal bovine serum (Hyclone, USA), $100 \mathrm{mg} / \mathrm{L}$ streptomycin, and $16 \mathrm{mg} / \mathrm{L}$ penicillin at $37^{\circ} \mathrm{C}$ in $5 \% \mathrm{CO}_{2}$. The A549 cells were seeded into 24 -well plates with $1 \times 10^{5} /$ wells and cultured in RPMI 1640 with $10 \% \mathrm{FBS}$ for $16 \mathrm{~h}$ to $18 \mathrm{~h}$ before being infected with conidia.

\section{Establishment of an in vitro infection model}

Following the incubation process, an amount of $1 \times 10^{4}$ conidia was added to each well in each experimental group, with the wells then incubated for $6 \mathrm{~h}$ at $37^{\circ} \mathrm{C}$. The cells were washed five times with PBS to remove unattached conidia. Amounts of five hundred microliters of RIPA buffer (iNtRON, Seoul, Korea) were added to the wells to disrupt the cells membrane and release the intracellular conidia. Lysates $(50 \mu \mathrm{L})$ was incubated on potato-dextrose agar plates for $36 \mathrm{~h}$ at $37^{\circ} \mathrm{C}$. The invasiveness of the conidia was calculated using the following formula: mean of colony-forming units $\times 1000 / 50$.

\section{Cloning of PU.1 and transfection}

Total RNA was isolated from $1 \times 10^{6}$ A549 cells using Easy-Spin $^{\text {TM }}$ Total RNA extraction kits with DNase I (iNtRON, Korea) following the manufacturer's protocol. RT-PCR was performed using a One-Step RT-PCR kit (QIAGEN, Valencia, CA, USA). The primers used were 5'-GAA TTC AGG CGT GCA AAA TGG AAG GG-3' (sense) and 5'-CTC GAG TCA GTG GGG CGG GTG GCG CC-3' (antisense). I transfected the plasmid into the cells with Lipofectamine ${ }^{\circledR} 2000$ (Invitrogen, Carlsbad, CA, USA). For each transfection, I used pcDNA3.1-PU.1 or $2 \mu \mathrm{L}$ of a siRNA duplex (SC-36330, Santa Cruz Biotech, TX, USA) into $100 \mu \mathrm{L}$ of the transfection medium.

\section{qRT-PCR}

Total RNA ( $2 \mu \mathrm{g}$ in a total volume of $20 \mu \mathrm{L})$ was used for reverse transcription. Quantitative RT-PCR was performed according to the manufacturer's instructions (Qiagen, USA) using a Rotor-Gene Q device (Qiagen, USA). Each run was assayed three times with $2 \times$ qPCR SYBR Green Mix kits (Doctor Protein, Korea) and $100 \mathrm{mM}$ of each primer. Primers sets (Table 1) were used to detect SP-A, SP-B, SP-C, SP-D (Che et al., 2012), PU.1 and $\beta$-actin (Kim et al., 2008).

The one-step qRT-PCR conditions were as follows: $42^{\circ} \mathrm{C}$ (40 min) for reverse transcription and $95^{\circ} \mathrm{C}$ (15 min) for one cycle, followed by $95^{\circ} \mathrm{C}(30 \mathrm{~s})$ and $55^{\circ} \mathrm{C}(30 \mathrm{~s})$ for 40 
Table 1. List of the Sequences of Primers for RT-PCR

\begin{tabular}{cll}
\hline \hline \multicolumn{2}{c}{ Genes } & \multicolumn{1}{c}{ Sequences $\left(5^{\prime} \rightarrow\right.$ 3') } \\
\hline \multirow{2}{*}{ SP-A } & Sense & 5'-CTG TCC CAA GGA ATC CAG AG-3' \\
& Anti-sense & 5'-CCG TCT GAG TAG CGG AAG TC-3' \\
\hline \multirow{2}{*}{ SP-B } & Sense & 5'-CAC CAT GTT CCC CAT TCC TCT-3' \\
& Anti-sense & 5'-TCA TCC ATG GAG CAC CGG AGG ACG-3' \\
\hline \multirow{2}{*}{ SP-C } & Sense & 5'-CTG GTT ACC ACT GCC ACC TT-3' \\
& Anti-sense & 5'-TCA AGA CTG GGG ATG CTC TC-3' \\
\hline \multirow{2}{*}{ SP-D } & Sense & 5'-AGG AGC AAA GGG AGA AAG TGG G-3' \\
& Anti-sense & 5'-CAG CTG TGC CTC CGT AAA TGG-3' \\
\hline \multirow{2}{*}{ PU.1 } & Sense & 5'-CAG CTC AGA TGA GGA G-3' \\
& Anti-sense & 5'-CTT GGA CGA GAA CTG GAA G-3' \\
\hline \multirow{2}{*}{$\beta$-actin } & Sense & 5'-GCC AAC ACA GTG CTG TCT GG-3' \\
& Anti-sense & 5'-TAC TCC TGC TTG CTG ATC CA-3' \\
\hline
\end{tabular}

cycles. Amplification of the target DNA was checked by means of a melting curve analysis from $55^{\circ} \mathrm{C}$ to $95^{\circ} \mathrm{C}$ $\left(+0.5^{\circ} \mathrm{C}\right.$ ramping for $\left.10 \mathrm{~s}\right)$. I analyzed the data using the $\mathrm{Ct}$ method to calculate the ratio between the experimental group and the control group. To verify the contamination of the DNA, I used the sample without primers as a negative control. Three independent biological replicates were carried out.

\section{RESULTS}

The surfactant protein family, SP-C and SP-D, were suppressed in A. fumigatus conidia-infected A549 cells

The function of the SP family in the pathogenesis of $A$. fumigatus infection is controversial. To investigate the role of surfactant proteins in a fungal infection, I examined the surfactant protein family expression levels in A. fumigatus conidia-infected A549 cells. After the incubation and isolation of RNA in conidia-infected cells, I ran qRT-PCR assays to determine the SP family transcript expression level.

The conidia infection of $A$. fumigatus caused the suppression of SP-C and SP-D expression levels in the surfactant protein family. In addition, the results showed that SP-D responded to the conidia concentration when the exposure level was high ( $10^{7}$ cells) (Fig. 1). I also found that the surfactant protein responds to the amount of A. fumigatus conidia in a dose-dependent manner. Thus, my result suggests that the SP-D gene expression level is suppressed by the direct infection of $A$. fumigatus conidia.

\section{PU.1 mRNA is also suppressed in $A$. fumigatus conidia- infected A549 cells}

The potential role of PU.1 in the pathogenesis of an infection of A. fumigatus remains unknown. To investigate the significance of PU.1 during the infection process, I assessed its expression level in A. fumigatus conidia-infected cells.

When I induced the suppression of SP-D in conidiainfected cells, I found that PU.1 mRNA was also suppressed (Fig. 2). This result provides evidence that the infection of A. fumigatus conidia leads to the down-regulation of PU.1 in cells.

\section{SP-D expression is increased in PU.1-transfected cells}

I have shown that SP-D and PU.1 are suppressed in cells infected with $A$. fumigatus conidia. However, research has not demonstrated the function of PU.1 as a regulator of SP-D expression. I investigated whether PU.1 has a role in increasing SP-D expression levels. I transfected the PU.1 expression vector $(1 \mu \mathrm{g} / \mu \mathrm{L})$ transiently (Fig. 3A) and checked the SP expression levels in cells by means of qRT-PCR assays. When PU.1 was over-expressed in A549 cells, only SP-D was increased in the cells (Fig. 3B). I therefore found 

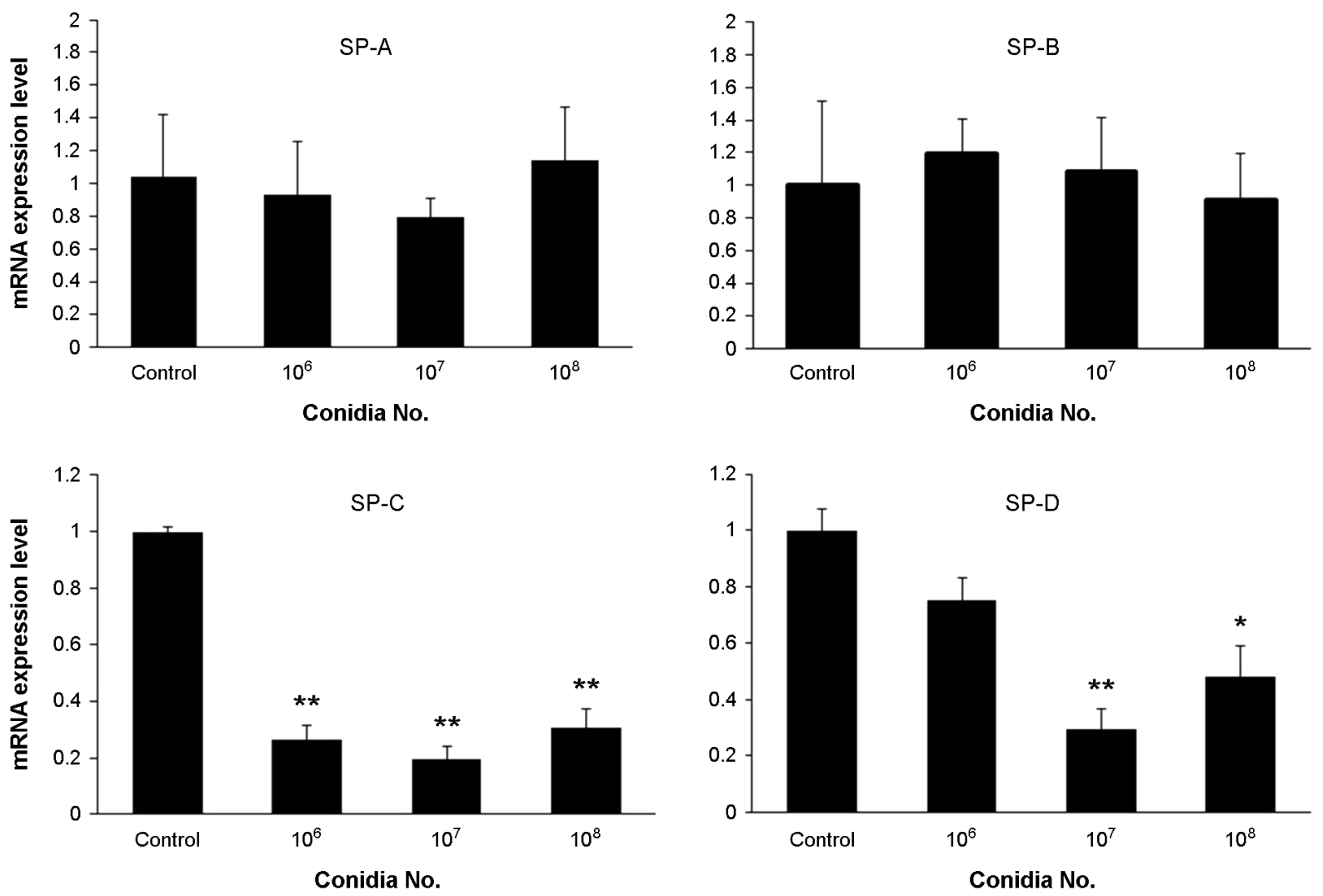

Fig. 1. Effects of the number of conidia on surfactant protein mRNA expression levels in human A549 cells. Relative mRNA expression of surfactant protein family members of $A$. fumigatus-infected cells. $* P<0.05$ and $* * P<0.01$.

that PU.1 serves as a positive regulator of the SP-D expression levels in this case.

\section{A. fumigatus invasion is decreased in PU.1 transfected A549 cells}

Mice lacking SP-D are protected during an infection of Cryptococcus neoformans (C. neoformans), whereas the increased SP-D enhances $C$. neoformans growth in organs (Geunes-Boyer et al., 2012). I sought to determine how the increased SP-D level through PU.1 activity influences an $A$. fumigatus conidia infection. To address the role of PU.1 during the infection process of A. fumigatus conidia, I transiently transfected the PU.1 expression vector into A549 cells and infected the cells with $A$. fumigatus conidia. In addition, I checked whether the SP-D expression level was increased by PU.1 transfection. My findings showed that the invasion of A. fumigatus was inhibited in cells transfected

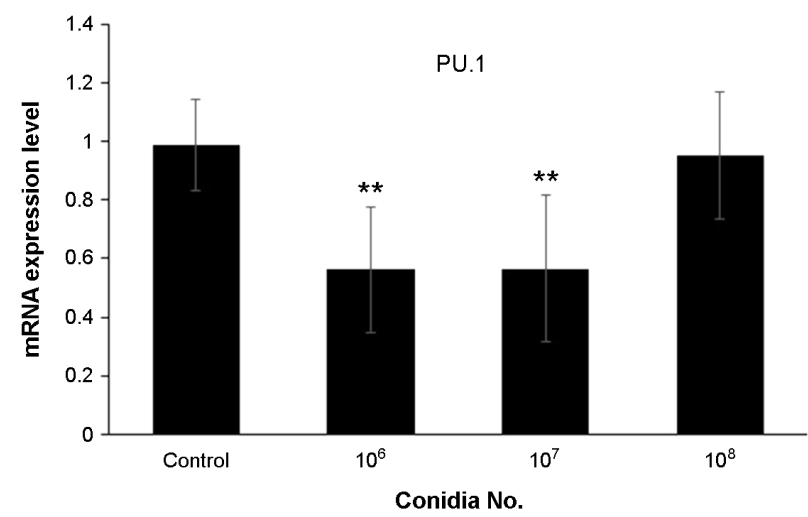

Fig. 2. mRNA expression of PU.1 in A. fumigatus-infected cells. Significance was determined by Student's $t$-tests. $* * P<0.01$.

by a relatively high concentration ( $8 \mu \mathrm{g}$ ) of PU.1 (Fig. 4).

One question is whether the infection of $A$. fumigatus conidia is increased in SP-D-suppressed cells when the PU.1 
(A)

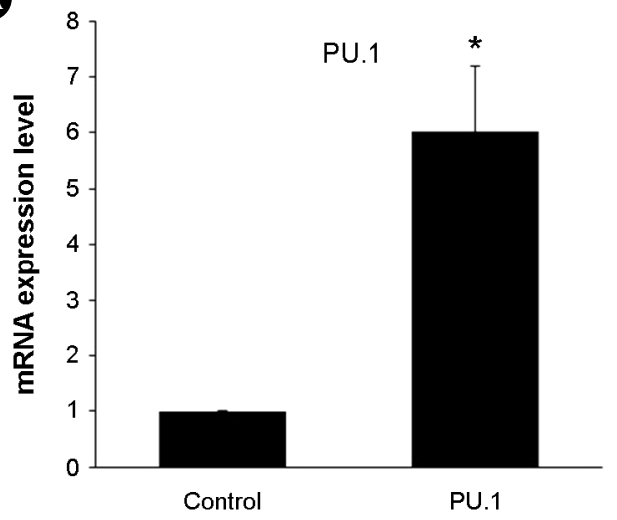

B

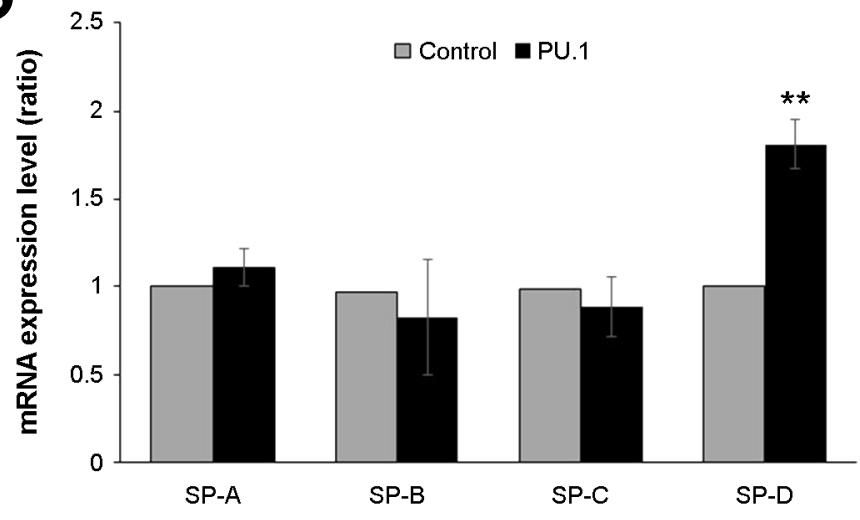

Fig. 3. Effects of PU.1 on surfactant protein mRNA expression levels in human A549 cells: (A) PU.1 mRNA expression level for PU.1transfected cells. (B) mRNA expression level of members of the surfactant protein family in PU.1-transfected cells. ${ }^{*} P<0.05,{ }^{* *} P<0.01$.

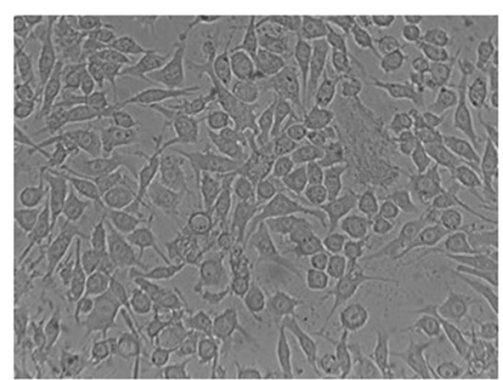

$0 \mu \mathrm{g}$

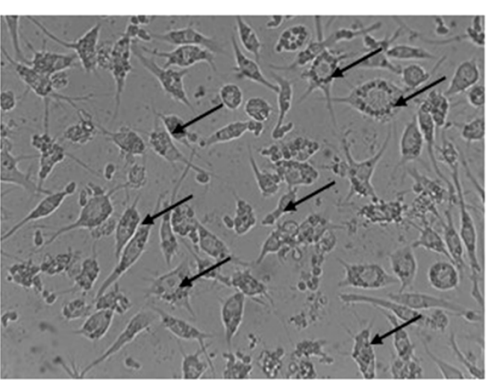

$6 \mu \mathrm{g}$

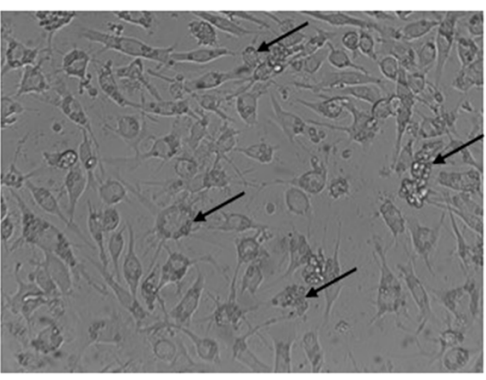

$8 \mu \mathrm{g}$

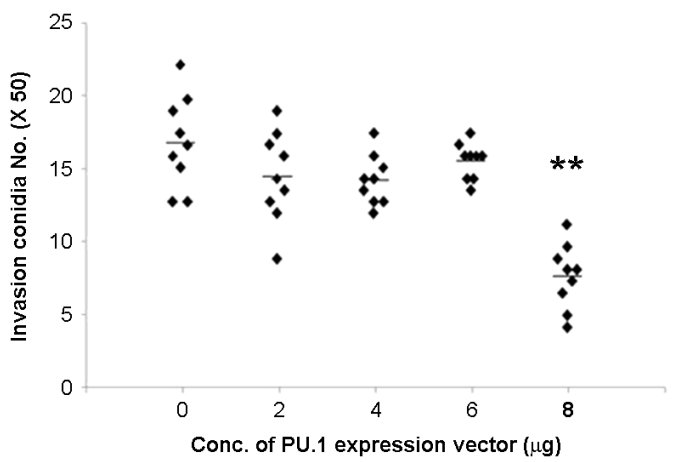

Fig. 4. Effects of the PU.1 concentration on instances of $A$. fumigatus conidia invasion in human A549 cells. Significance was determined by Student's $t$-tests, with $* * P<0.01$.

function is suppressed with its siRNA, leading to decreased SP-D levels.

Although PU.1 (Fig. 5A) and SP-D (Fig. 5B) were suppressed in cells treated with siRNA against PU.1, I observed that the invasion of A. fumigatus conidia did not increase in the PU.1-suppressed condition (Fig. 5C).
I summarized that $A$. fumigatus conidia readily induced the suppression of PU.1 and the SP-D expression level for infection and that PU.1 functions to protect cells from $A$. fumigatus conidia during an infection. 

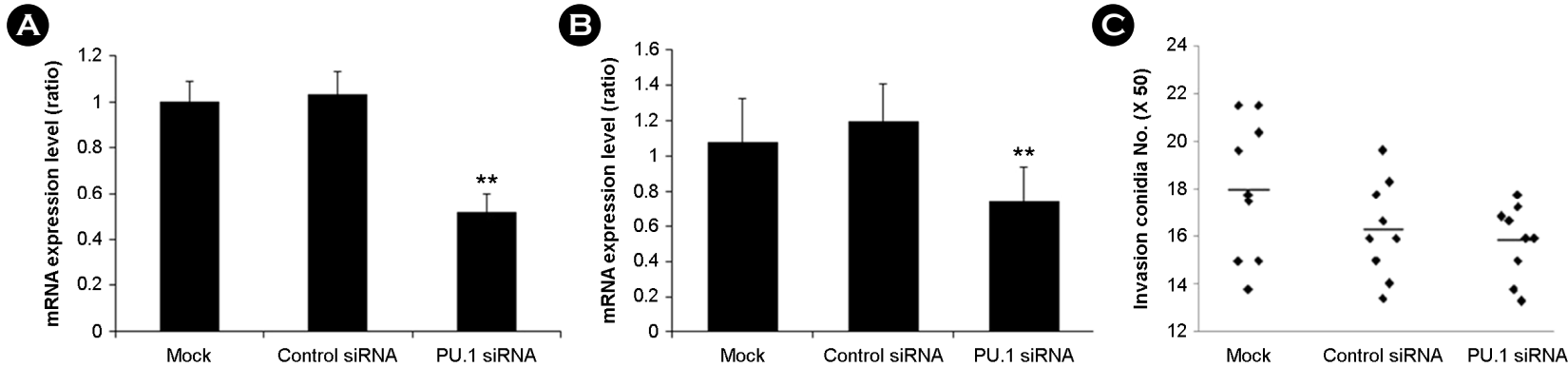

Fig. 5. Effects of PU.1 siRNA on human A549 cells: (A) mRNA expression level of PU.1 from PU.1 siRNA-treated cells. (B) mRNA expression level of SP-D in PU.1 siRNA-treated cells. (C) Invasion assay of A. fumigatus on PU.1 siRNA-treated cells. ${ }^{* *} P<0.01$.

\section{DISCUSSION}

Aspergillosis represents a severe threat to immunosuppressed individuals; hence, developing a new therapeutic roadmap will help defend them and improve their clinical outcomes. My study found that PU.1 is a positive regulator of the expression of SP-D in A. fumigatus conidia-infected cells. Moreover, infections of $A$. fumigatus conidia are decreased in SP-D overexpressed cells.

SP-D has several functions in the regulation of the innate immune response in the lung (Wright, 2005). For example, SP-D suppresses the dissemination of infectious microbes by inhibiting their behaviors by, for example, agglutination and growth suppression (Wu et al., 2003). Moreover, SP-D enhances the elimination of microbes by assisting with the phagocytosis of macrophages. SP-D also interacts with pattern-recognition receptors such as toll-like receptors $\mathrm{CD} 14$ and MD-2 and thus regulates inflammatory responses (Ohya et al., 2006). Additionally, SP-D has been used to induce various cytokines and chemokines in an effort to increase the clearance of bacterial, viral, and fungal pathogens. The protective roles of SP-D during bacterial and viral infections have been thoroughly investigated (Giannoni et al., 2006). However, its expression mechanism during infections of fungi has not been characterized as well, though many fungal studies have been conducted with $A$. fumigatus.

Inflammation induced by $A$. fumigatus is related to increased SP-D protein expression levels (Haczku et al., 2001). However, my data demonstrated that SP-C and SP-D in the SP family are only suppressed in conidia-infected cells and that they respond in a dose-dependent manner. I found that SP-D expression levels in infected cells are increased to protect the cells.

Serum SP-D levels in allergic patients, those with hypersensitive lung disease, and asthmatics have been found to be increased upon medical diagnosis and decreased following corticosteroid therapy (Tanaka et al., 2000). Patients with idiopathic pulmonary fibrosis have high blood SP-D levels, and high SP-D levels are detected in the blood in those with interstitial pneumonia during collagen vascular disease and pulmonary alveolar proteinosis (Takahashi et al., 2000).

PU.1 is a well-known principal transcriptional regulator of innate immunity. PU.1 is decreased significantly in monocytes infected with Ehrlichia chaffeensis (Lin and Rikihisa, 2004). However, in human monocyte leukemia cells infected with A. fumigatus conidia, the protein expression level, not the mRNA, of PU.1 is increased (Wang et al., 2016). My results here showed that PU.1 is also suppressed in $A$. fumigatus conidia-infected cells. When I increased the PU.1 expression level, there was a significant decrease in conidia invasion into the cells. NFATc3 and TTF-1 directly interact with each other and synergistically activate SP-D expression during the transcription processes (Dave et al., 2004). C/EBP elements can also modulate the promoter activity of SP-D with interactions in the near-distal promoter region (He and Crouch, 2002). AP-1 proteins modulate SP-D gene expression levels in pulmonary epithelial cells during transcriptional activity (He et al., 2000). However, I did not observe any increase in infected conidia in A549 cells transfected with siRNA specific to PU.1. 
This study suggests that PU.1 serves as a positive regulator of SP-D expression as a transcription factor and that the increased amount of SP-D protects cells from A. fumigatus infection. The findings here clearly indicate that transcription factor PU.1 is a good regulator during an A. fumigatus conidia infection via SP-D and that it is a potential candidate for use in aspergillosis treatments.

\section{ACKNOWLEDGEMENTS}

This work was supported by the Basic Science Research Program through the National Research Foundation of Korea, funded by the Ministry of Education, Science, and Technology with grants to S.S. Kim (NRF- 2017R1D1A1B03032671). This work was also supported by a research grant from Daejeon University to S.S. Kim. I also gratefully acknowledge Kwang-Soo Shin (Daejeon University) for valuable discussion and providing the A. fumigates, and other reagents.

\section{CONFLICTS OF INTEREST}

The authors declare that they do not have any conflicts of interest to disclose.

\section{REFERENCES}

Augusto LA, Synguelakis M, Espinassous Q, Lepoivre M, Johansson J, Chaby R. Cellular antiendotoxin activities of lung surfactant protein $\mathrm{c}$ in lipid vesicles. Am J Respir Crit Care Med. 2003. 168: 335-341.

Barnes PD, Marr KA. Aspergillosis: Spectrum of disease, diagnosis, and treatment. Infect Dis Clin North Am. 2006. 20: 545-561.

Che CY, Jia WY, Xu Q, Li N, Hu LT, Jiang N, Lin J, Wang Q, Zhao GQ. The roles of surfactant protein $d$ during aspergillus fumigatus infection in human corneal epithelial cells. Int $\mathbf{J}$ Ophthalmol. 2012. 5: 13-17.

Dave V, Childs T, Whitsett JA. Nuclear factor of activated t cells regulates transcription of the surfactant protein $\mathrm{d}$ gene (sftpd) via direct interaction with thyroid transcription factor-1 in lung epithelial cells. J Biol Chem. 2004. 279: 34578-34588.

Geunes-Boyer S, Beers MF, Perfect JR, Heitman J, Wright JR. Surfactant protein $\mathrm{d}$ facilitates cryptococcus neoformans infection. Infect Immun. 2012. 80: 2444-2453.

Giannoni E, Sawa T, Allen L, Wiener-Kronish J, Hawgood S.
Surfactant proteins a and d enhance pulmonary clearance of pseudomonas aeruginosa. Am J Respir Cell Mol Biol. 2006. 34: 704-710.

Gombart AF, Kwok SH, Anderson KL, Yamaguchi Y, Torbett BE, Koeffler HP. Regulation of neutrophil and eosinophil secondary granule gene expression by transcription factors c/ebp epsilon and pu.1. Blood. 2003. 101: 3265-3273.

Haczku A, Atochina EN, Tomer Y, Chen H, Scanlon ST, Russo S, $\mathrm{Xu}$ J, Panettieri RA, Jr., Beers MF. Aspergillus fumigatusinduced allergic airway inflammation alters surfactant homeostasis and lung function in balb/c mice. Am J Respir Cell Mol Biol. 2001. 25: 45-50.

He Y, Crouch E. Surfactant protein d gene regulation. Interactions among the conserved ccaat/enhancer-binding protein elements. J Biol Chem. 2002. 277: 19530-19537.

He Y, Crouch EC, Rust K, Spaite E, Brody SL. Proximal promoter of the surfactant protein $d$ gene: Regulatory roles of ap-1, forkhead box, and gt box binding proteins. J Biol Chem. 2000. 275: 31051-31060.

Henkel G, Brown MA. Pu.1 and gata: Components of a mast cell-specific interleukin 4 intronic enhancer. Proc Natl Acad Sci U S A. 1994. 91: 7737-7741.

Kafer E. Meiotic and mitotic recombination in aspergillus and its chromosomal aberrations. Adv Genet. 1977. 19: 33-131.

Karpurapu M, Wang X, Deng J, Park H, Xiao L, Sadikot RT, Frey RS, Maus UA, Park GY, Scott EW, Christman JW. Functional pu. 1 in macrophages has a pivotal role in nf-kappab activation and neutrophilic lung inflammation during endotoxemia. Blood. 2011. 118: 5255-5266.

Kim SS, Romero R, Kim JS, Abbas A, Espinoza J, Kusanovic JP, Hassan S, Yoon BH, Kim CJ. Coexpression of myofibroblast and macrophage markers: Novel evidence for an in vivo plasticity of chorioamniotic mesodermal cells of the human placenta. Lab Invest. 2008. 88: 365-374.

Lawrence T, Natoli G. Transcriptional regulation of macrophage polarization: Enabling diversity with identity. Nat Rev Immunol. 2011. 11: 750-761.

LeVine AM, Kurak KE, Bruno MD, Stark JM, Whitsett JA, Korfhagen TR. Surfactant protein-a-deficient mice are susceptible to pseudomonas aeruginosa infection. Am J Respir Cell Mol Biol. 1998. 19: 700-708.

Lin M, Rikihisa Y. Ehrlichia chaffeensis downregulates surface toll-like receptors $2 / 4$, cd14 and transcription factors pu.1 and inhibits lipopolysaccharide activation of nf-kappa b, erk 1/2 and p38 mapk in host monocytes. Cell Microbiol. 2004 
6: 175-186.

McCormack FX, Gibbons R, Ward SR, Kuzmenko A, Wu H, Deepe GS, Jr. Macrophage-independent fungicidal action of the pulmonary collectins. J Biol Chem. 2003. 278: 36250 -36256 .

Ohya M, Nishitani C, Sano H, Yamada C, Mitsuzawa H, Shimizu T, Saito T, Smith K, Crouch E, Kuroki Y. Human pulmonary surfactant protein $\mathrm{d}$ binds the extracellular domains of tolllike receptors 2 and 4 through the carbohydrate recognition domain by a mechanism different from its binding to phosphatidylinositol and lipopolysaccharide. Biochemistry. 2006. 45: 8657-8664.

Qian F, Deng J, Lee YG, Zhu J, Karpurapu M, Chung S, Zheng JN, Xiao L, Park GY, Christman JW. The transcription factor pu. 1 promotes alternative macrophage polarization and asthmatic airway inflammation. J Mol Cell Biol. 2015. 7: 557-567. Segal BH. Aspergillosis. N Engl J Med. 2009. 360: 1870-1884.

Sharon H, Amar D, Levdansky E, Mircus G, Shadkchan Y, Shamir $\mathrm{R}$, Osherov N. Prtt-regulated proteins secreted by aspergillus fumigatus activate mapk signaling in exposed a549 lung cells leading to necrotic cell death. PLoS One. 2011. 6: e17509.

Takahashi H, Kuroki Y, Tanaka H, Saito T, Kurokawa K, Chiba H, Sagawa A, Nagae H, Abe S. Serum levels of surfactant proteins a and $\mathrm{d}$ are useful biomarkers for interstitial lung disease in patients with progressive systemic sclerosis. Am J Respir Crit Care Med. 2000. 162: 258-263.

Tanaka H, Sugawara H, Saikai T, Tsunematsu K, Takahashi H, Abe S. Mushroom worker's lung caused by spores of hypsizigus marmoreus (bunashimeji): Elevated serum surfactant protein d levels. Chest. 2000. 118: 1506-1509.

Wang M, Liu Z, Liu C, Wu T, Cai F, Wang Q, Su X, Shi Y. Pu.1 is involved in the immune response to aspergillus fumigatus through upregulating dectin-1 expression. BMC Infect Dis. 2016. 16: 297.

Whitsett JA, Weaver TE. Hydrophobic surfactant proteins in lung function and disease. N Engl J Med. 2002. 347: 2141-2148.

Wright JR. Immunoregulatory functions of surfactant proteins. Nat Rev Immunol. 2005. 5: 58-68.

Wu H, Kuzmenko A, Wan S, Schaffer L, Weiss A, Fisher JH, Kim KS, McCormack FX. Surfactant proteins a and d inhibit the growth of gram-negative bacteria by increasing membrane permeability. J Clin Invest. 2003. 111: 1589-1602.

Yan C, Wu M, Cao J, Tang H, Zhu M, Johnson PF, Gao H. Critical role for ccaat/enhancer-binding protein beta in immune complex-induced acute lung injury. J Immunol. 2012. 189: 1480-1490.

Zhou L, Lim L, Costa RH, Whitsett JA. Thyroid transcription factor-1, hepatocyte nuclear factor-3beta, surfactant protein $\mathrm{b}$, c, and clara cell secretory protein in developing mouse lung. J Histochem Cytochem. 1996. 44: 1183-1193.

https://oi.org/10.15616/BSL.2018.24.3.175

Cite this article as: Kim SS. Transcription Factor PU.1 Inhibits Aspergillus fumigatus Infection via Surfactant Protein-D. Biomedical Science Letters. 2018. 24: 175-182. 